\title{
Analysis of DFW Perimeter Taxiway Operations
}

\begin{tabular}{|r|l|}
\hline Journal: & 2010 AIAA ATIO/ISSMO Conference \\
\hline Manuscript ID: & Draft \\
\hline luMeetingID: & 2280 \\
\hline Date Submitted by the \\
Author: & n/a \\
\hline Contact Author: & Engelland, Shawn \\
\hline
\end{tabular}

\section{SCHOLARONE ${ }^{m}$ Manuscripts}




\title{
Analysis of DFW Perimeter Taxiway Operations
}

\author{
Shawn A. Engelland ${ }^{*}$ \\ NASA Ames Research Center, Fort Worth, TX 76155 \\ Louise Morgan Ruszkowski ${ }^{\dagger}$ \\ Flatirons Solutions, Inc., Irving, TX 75063
}

\begin{abstract}
This study examines operations of the perimeter taxiway system at Dallas/Fort Worth International Airport (DFW) to characterize and understand the impact of the perimeter taxiway system and to provide operational decision makers with guidance on use of this new airport resource. DFW's perimeter taxiway entered service in December 2008 and is representative of perimeter or end-around taxiways currently in use at several other airports worldwide. This perimeter taxiway analysis is a collaborative effort between NASA and various DFW stakeholders including the FAA, air carriers and the airport operator. The initial investigation has focused on quantifying perimeter taxiway usage and assessing effects on taxi times at both the local and global levels. Local-level results show taxi times via the perimeter taxiway to be about forty-five seconds longer on average, but with significantly less variability. Global-level results show average perimeter taxiway times to be a little more than one minute longer with variability that is comparable to that for other taxi paths.
\end{abstract}

\section{Introduction}

$\mathrm{P}$ ERIMETER or End-Around Taxiways have garnered considerable interest in recent years due to the twin promises of enhanced safety and improved airport efficiency. Aircraft using perimeter taxiways generally taxi farther and experience longer unimpeded taxi times than aircraft on conventional taxiways; however, perimeter taxiway advocates argue that these negatives are offset by reduced potential for runway incursions, fewer required clearances (i.e. reduced frequency congestion), increased runway throughput, and potential fuel savings and emissions reduction due to non-stop taxi flows. Fast-time and human-in-the-loop simulations have been used to project perimeter taxiway benefits and to identify human factors or other operational challenges. Since few perimeter taxiways have been implemented, these previous simulation experiments depended heavily on projected usage patterns.

DFW International Airport implemented the first quadrant of a proposed full-airport perimeter taxiway system in December 2008. Prior to implementation, an informal team of DFW stakeholders (FAA, air carriers, the airport operator and NASA) engaged in numerous technical interchange meetings to discuss utilization of the new taxiway and methods for assessing performance of the new system once implemented. NASA's North Texas Research Station (NTX) is contributing data collection capabilities, analysis tools and technical expertise to the DFW perimeter taxiway performance assessment effort. The objective of this assessment is to help DFW stakeholders better understand the operational impact of the perimeter taxiway system and refine guidelines on use of the perimeter taxiway.

This study analyzes sixteen months of actual DFW perimeter taxiway operations to: (1) quantify usage of the perimeter taxiway, (2) assess local-level taxi time impacts by comparing taxi times for the perimeter taxiway with taxi times for the nearest alternative taxiway, and (3) assess global-level taxi time impacts by comparing overall movement area taxi times for aircraft using the perimeter taxiway with times for those using other taxiways.

\section{Background}

Perimeter taxiways are currently in use at just a few airports worldwide. Frankfurt/Main (EDDF) may have introduced the concept with what has been described as a "de-facto perimeter taxiway system"1 utilizing taxiways

\footnotetext{
${ }^{*}$ Aerospace Engineer, NASA/FAA North Texas Research Station, AIAA Senior Member.

${ }^{\dagger}$ Aerospace Engineer, NASA/FAA North Texas Research Station.
} 
(Bravo-East, Sierra and Whiskey) linking the primary ramp with the former Rhein-Main airbase ramp to the south. Amsterdam Schiphol (EHAM) included a perimeter taxiway as an integral part of the "Polderbaan" runway (i.e. 18R/36L) which opened in 2002. Taxiways Yankee and Zulu route Polderbaan traffic around the north and south ends of runway 18C/36C at EHAM. In April 2007, Atlanta Hartsfield-Jackson (KATL) opened the first purposebuilt perimeter taxiway in the US. ${ }^{2}$ Taxiway Victor serves KATL's north-side runway complex routing runway 26R arrival traffic around (and below) the departure end of runway 26L. In late 2008, Dallas/Fort Worth International Airport (KDFW) opened the southeast quadrant perimeter taxiway, which is described in detail below. A number of proposed perimeter taxiways are currently under study and some airports are introducing procedures that establish "virtual" perimeter taxiways using existing resources. Examples of the latter include the displaced thresholds employed in the Chicago O'Hare (KORD) modernization plan ${ }^{1}$ and the new taxi and takeoff procedures for the south-side runway complex at KATL. ${ }^{3}$

\section{A. Dallas/Fort Worth Southeast Quadrant Perimeter Taxiway}

The DFW airport development plan ${ }^{4}$ envisions four perimeter taxiways located at each end of the primary north/south runway pairs. These four perimeter taxiway projects are in various stages of design and development. The southeast quadrant perimeter taxiway entered service on 22 December 2008.

Figure 1 is an annotated version of the standard FAA airport diagram for DFW. Some elements of this figure are illegible due to space constraints. The reader is encouraged to consult a current DFW airport diagram to supplement this figure. As shown in Fig. 1, DFW's southeast quadrant perimeter taxiway routes aircraft around the south end of runways $17 \mathrm{R}$ and $17 \mathrm{C}$. The perimeter taxiway is comprised of extensions to existing taxiways $\mathrm{P}, \mathrm{M}$, and JS south of ER, plus a new east-west connecting taxiway (ES). It was designed to serve both runways $17 \mathrm{C}$ and $17 \mathrm{~L}$ - the main

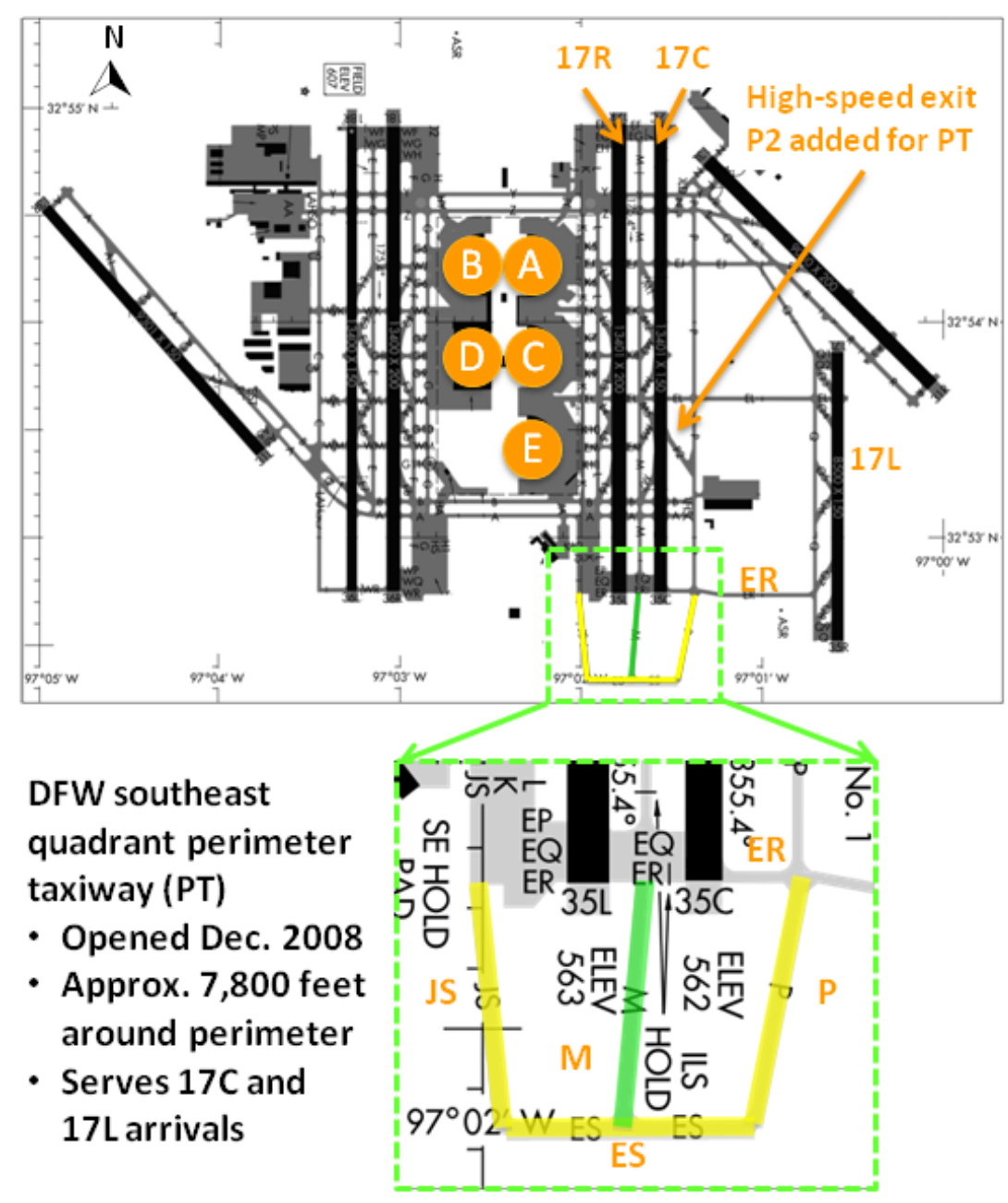
south flow arrival runways on the airport's east side.

Prior to perimeter taxiway implementation, runway 17C arrivals would typically take one of the west high-speed exits to taxiway $\mathrm{M}$ (north-south taxiway between 17R and 17C). These aircraft would then be staged on one of the many east-west connector taxiways to wait for an opportunity to cross $17 \mathrm{R}$ (the primary east-side departure runway). 17L arrivals would typically taxi via ER and be staged to cross $17 \mathrm{C}$ and $17 \mathrm{R}$. In some cases, 17L arrivals would be directed north along taxiway $\mathrm{P}$ (north-south taxiway east of 17C) to help balance the queues waiting to cross $17 \mathrm{C}$ and $17 \mathrm{R}$.

Use of the perimeter taxiway is constrained by flow direction and aircraft tail height. Current FAA policy established by the Airport Obstructions Standards Committee (AOSC) ${ }^{5,6,7}$ permits only departing aircraft to overfly an operational perimeter taxiway. Since DFW's perimeter taxiway is on the departure end of runways $17 \mathrm{R}$ and $17 \mathrm{C}$ it can only be used when the airport is in a south flow configuration. South

Figure 1. DFW southeast quadrant perimeter taxiway. 
flow prevails at DFW approximately $70 \%$ of the time.

The FAA AOSC decision documents ${ }^{5,6,7}$ also provide obstacle clearance criteria that result in aircraft height restrictions for perimeter taxiway operations. DFW perimeter taxiway tail height limitations are illustrated in Fig. 2. One can see from the figure that nearly all aircraft may use the exterior segments of the perimeter taxiway depicted in yellow. However, the taxiway $M$ extension (shown in green) is limited to aircraft with tail heights less than or equal to 46 feet (i.e. B757s and smaller). Runway 17C arrival traffic with tail heights greater than 46 feet must either take the new eastbound high-speed exit to the perimeter taxiway (i.e. exit P2 to

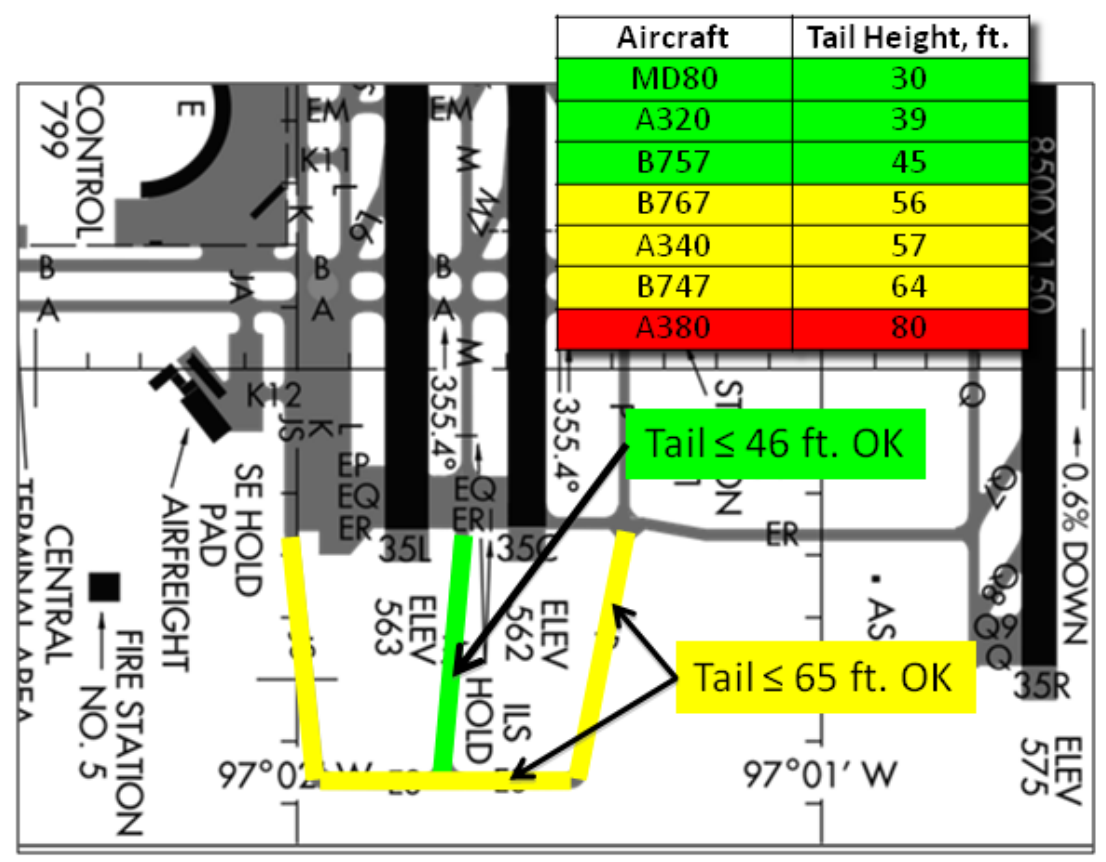

Figure 2. Tail height restrictions for DFW perimeter taxiway. taxiway P) or they must exit to the west and cross runway 17R. As indicated by the table in Fig. 2, the A380 exceeds tail height limits for DFW's perimeter taxiway. This is not currently a factor as no A380s operate at the airport and DFW's Airfield Implementation Plan specifies that the A380 will operate only on the west side of the airport.

Typical perimeter taxiway taxi routes for runways 17L and 17C are shown in Fig. 3. As shown later, runway 17L arrivals are the primary users of the perimeter taxiway. The taxi route for these aircraft is shown in Fig. 3a.

The tail height restrictions described above mandate two taxi route alternatives for runway 17C arrivals. Aircraft with tail heights less than or equal to 46 feet are permitted to take west perimeter route shown in Fig. 3b. Aircraft with tail heights greater than 46 feet must take the significantly longer (approximately 1,400 ft longer) east route illustrated in Fig. 3c.

In all three cases the air traffic controller with responsibility for runway operations (i.e. Local Control) will issue arrival traffic with a clearance to taxi via the perimeter taxiway with instructions to contact Ground Control after reaching the perimeter taxiway. A typical clearance for runway 17L arrivals would be:

Aircraft landing 17L: from taxiway Echo Romeo turn left on Papa then taxi via Echo Sierra and Juliet Sierra. Hold short of taxiway Alpha. Contact ground 121.8 south of Echo Romeo.

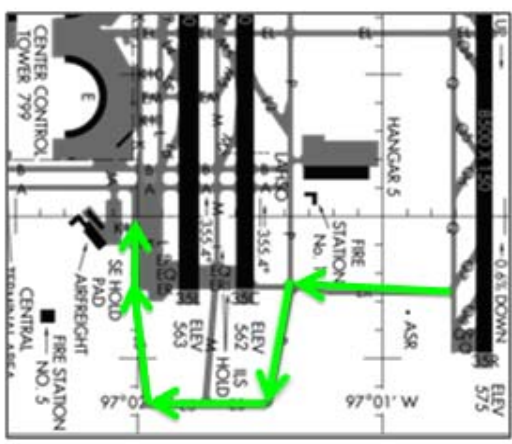

a) $17 \mathrm{~L}$ taxi route

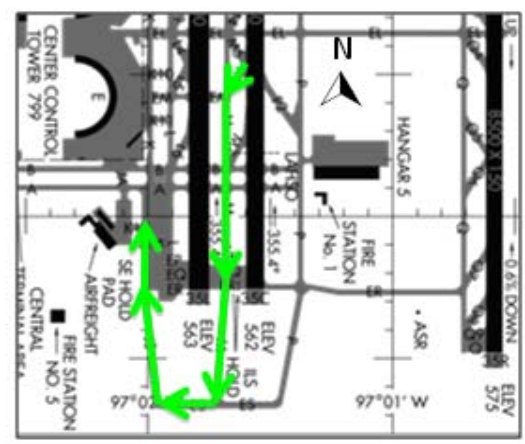

b) $17 \mathrm{C}$ west taxi route

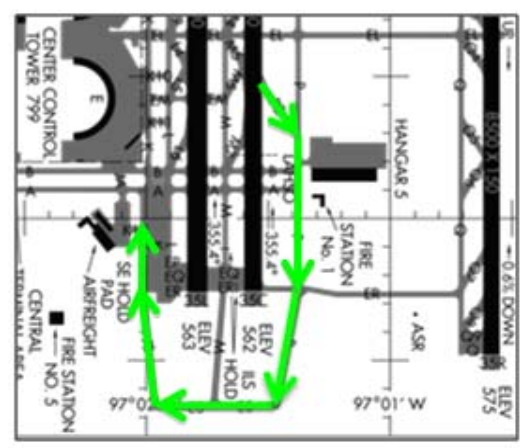

c) $17 \mathrm{C}$ east taxi route

Figure 3. Typical DFW perimeter taxiway routes for $17 \mathrm{~L}$ and $17 \mathrm{C}$ arrival traffic. 


\section{B. DFW Perimeter Taxiway Simulation Experiments}

Perimeter taxiway operational concepts and designs have been studied in numerous simulation experiments. This section summarizes published results from two simulations of DFW's perimeter taxiway system prior to its implementation.

\section{2003 Real-time human-in-the-loop experiment}

In February 2003, the Dallas/Fort Worth International Airport Perimeter Taxiway (DAPT) Demonstration ${ }^{8}$, sponsored by the FAA and DFW, was conducted at NASA's Future Flight Central facility. The demonstration included subject matter experts from DFW airport, the FAA, DFW air traffic controllers, pilots from several airlines, and NASA personnel. The demonstration was designed to simulate real-world DFW operations as they would occur both with and without perimeter taxiways, with both air traffic controllers and pilots in the loop.

The Future Flight Central tower cab simulated DFW's east air traffic control tower. A Boeing 747-400 simulator in the adjacent Crew-Vehicle Systems Research Facility was coupled with the FFC simulation to provide the flight deck perspective. DFW east-side operations were simulated, with the airport in south flow, in daytime VFR conditions with a ceiling of $5000 \mathrm{ft}$. and visibility of 5 miles. Elements of west-side traffic were included for realism, such as bridge traffic and arrivals and departures affecting the west side. Arrival and departure rates were set at $20-30 \%$ over circa 2003 peak-demand levels.

In the scenarios where the perimeter taxiways existed, they were located at both the south and north ends of the airport. $100 \%$ of the arrivals and departures in the perimeter taxiway runs utilized the perimeter taxiways by design. Thus, the perimeter taxiways completely eliminated runway crossings, for which the baseline had shown an average of $\sim 94 \mathrm{ac} /$ hour crossing runway $17 \mathrm{R}$ and $\sim 60 \mathrm{ac}$ /hour crossing runway 17C.

The simulation showed an average inbound taxi time increase per aircraft of $\sim 2: 07$ minutes $(\sim 18 \%)$. This average is further broken down by arrival runway as follows: an average increase in taxi time of 4:56 min. (54\%) for runway $17 \mathrm{C}$ arrivals, and an average decrease in taxi time of 1:16 min. (-8\%) for runway17L arrivals. The average outbound taxi time per aircraft decreased by $\sim 4: 28$ min ( 27\%), mainly due to less time spent in departure queues.

Results from this experiment also projected increased overall departure rates, reduction in the number of stops while taxiing and a reduction in pilot/controller communications for taxi clearances (i.e. reduced frequency congestion). The present study does not address these aspects of perimeter taxiway operations.

\section{2007 Fast-time simulation study}

In August 2007, Dr. Satyamangalam D. Satyamurti published a doctoral thesis that examined the safety and capacity enhancement impact of perimeter taxiways at DFW. ${ }^{9}$ Satyamurti used Visual SIMMOD to simulate airport operations both with and without the perimeter taxiways, at four specific levels for daily departure and arrival demand.

In the simulation ground rules, it was expected that all arrivals would use the appropriate perimeter taxiway, including arrivals landing on both $17 \mathrm{C}$ and $17 \mathrm{~L}$ using the south-east perimeter taxiway. Perimeter taxiways were assumed to be located at all four planned locations at DFW, with bridges connecting the two north perimeter taxiways and the two south perimeter taxiways. Fuel issues were not considered in the simulation.

For the baseline case, in south flow, comparing airport operations without the perimeter taxiway to those with the perimeter taxiway, the simulation results showed the following: an average overall increase in taxi in time of $5.67 \mathrm{~min}$. (from $11.26 \mathrm{~min}$. to $16.93 \mathrm{~min}$.), and an average overall decrease in taxi out time of $1.43 \mathrm{~min}$. (from 11.08 min. to $9.65 \mathrm{~min}$.) It also showed the wait time to cross a runway decreasing from an average of $0.68 \mathrm{~min} / \mathrm{ac}$ to 0 $\mathrm{min} / \mathrm{ac}$ for arrivals, and decreasing from an average of $0.53 \mathrm{~min} / \mathrm{ac}$ to $0 \mathrm{~min} / \mathrm{ac}$ for departures.

\section{Methodology}

This section begins with an overview of the data sources and analysis tools that were used in this study. Methods for calculating perimeter taxiway usage and computing local and global taxi times are then detailed.

\section{A. Data Sources and Analysis Tools}

NASA's North Texas Research Station (NTX) has developed a system to gather, merge and process a wide array of real-time air traffic management data. This system provides NASA researchers with live data feeds for shadow and operational evaluations of NextGen concepts and technologies. The NTX data collection system also includes a data warehouse and tools to support post-event analyses of air traffic operations such as those presented here. 
Figure 4 provides a sample of the surveillance data available via the NTX data collection system. This figure presents track data from a missed approach to runway 17C. As the aircraft executes the missed approach heading south from DFW runway 17C, two sets of track data may be observed. The closely spaced tracks (virtually a solid line in this figure) represent the

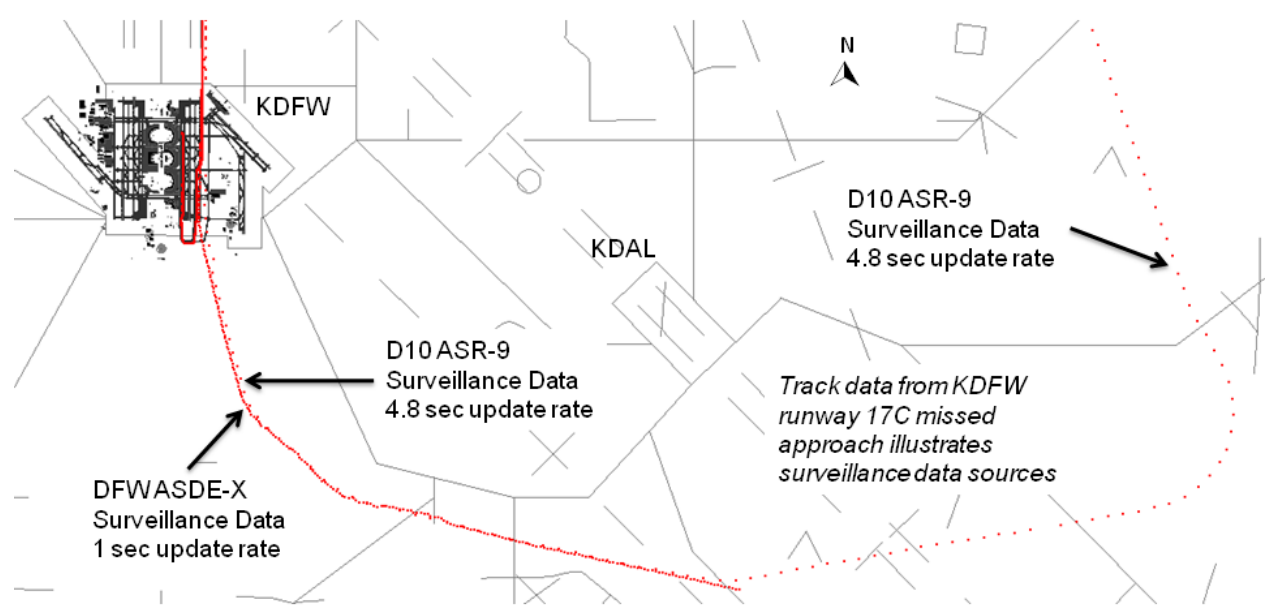

Figure 4. NTX data collection system sources illustrated.

$1 \mathrm{~Hz}$ track updates from DFW's ASDE-X surveillance system. The more widely spaced track hits are from D10 TRACON's ARTS IIIE which pulls data from four ASR-9 radar systems. Note as the aircraft passes to the south of Dallas Love Field (KDAL) it leaves the ASDE-X coverage area and the only aircraft track data are from the ASR-9. Finally as the aircraft returns to DFW both the ASDE-X and ASR-9 tracks can be seen. Though not apparent at this scale, the ASR-9 data drops out near the runway threshold, and ASDE-X provides the track data as the aircraft lands on runway $17 \mathrm{C}$ and taxis to Terminal A via the perimeter taxiway.

Figure 5 provides a more detailed view of how ASDE-X data is used to analyze DFW perimeter taxiway operations. The track data presented in this figure represent all perimeter taxiway operations (about 80) for a single

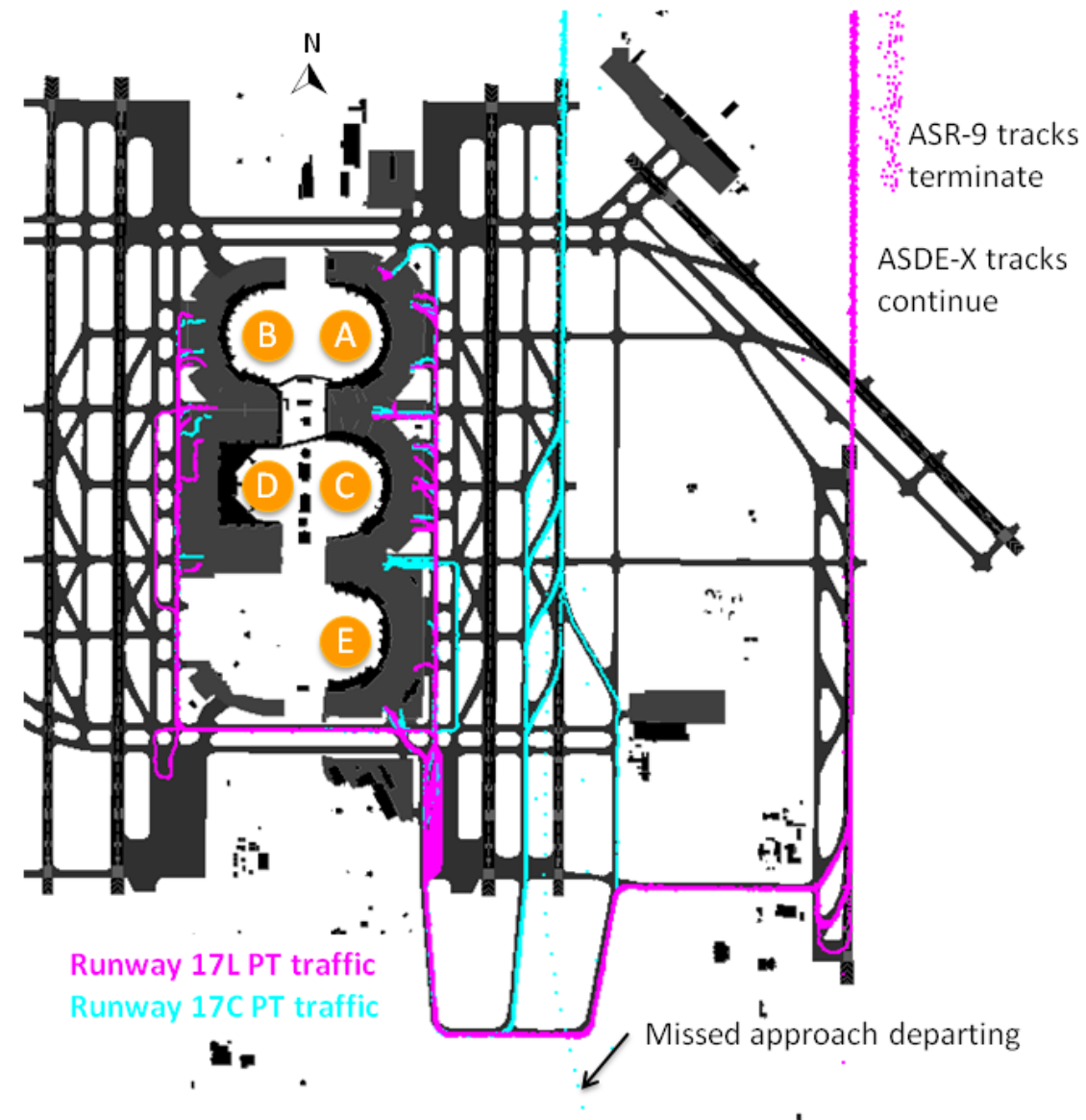

Figure 5. ASDE-X tracks for perimeter taxiway operations. day (2 July 2010). Runway 17L arrivals using the perimeter taxiway are shown in magenta. Runway 17C arrivals using the perimeter taxiways are shown in cyan. Use of the perimeter taxiway from runway 17C was unusually heavy on this date. One can see cyan tracks on all five 17C high-speed exits. Together Figs. 4 and 5 illustrate the value of drawing upon multiple data sources for postevent analyses.

Surveillance data gathered and processed by the NTX data collection system are then delivered to the Surface Operations Data Analysis and Adaptation (SODAA) tool ${ }^{10,11}$ where they are combined with data from other sources, refined and managed. During the import process, SODAA computes a wide array of derived elements, filling a complex relational database with more than 300 raw and derived data elements. SODAA provides researchers with a powerful query manager and several options for 5

American Institute of Aeronautics and Astronautics 
visualizing results, as well as data export capabilities that enable additional analysis with other tools. NTX uses SODAA to build and manage a database containing more than two years worth of DFW operational data.

This study focuses on three aspects of DFW perimeter taxiway operations: (1) perimeter taxiway usage, (2) local taxi times, and (3) global taxi times.

\section{B. Perimeter Taxiway Usage}

Perimeter taxiway usage counts rely on SODAA's ability to filter flights by geospatial region. SODAA's underlying adaptation divides the airport surface (both movement and ramp areas) into polygons. Figure 6a shows the polygons associated with the perimeter taxiway in green. Perimeter taxiway usage was determined by querying the SODAA database for all flights with track data in these polygons. The identified flights were then collated by date and arrival runway.

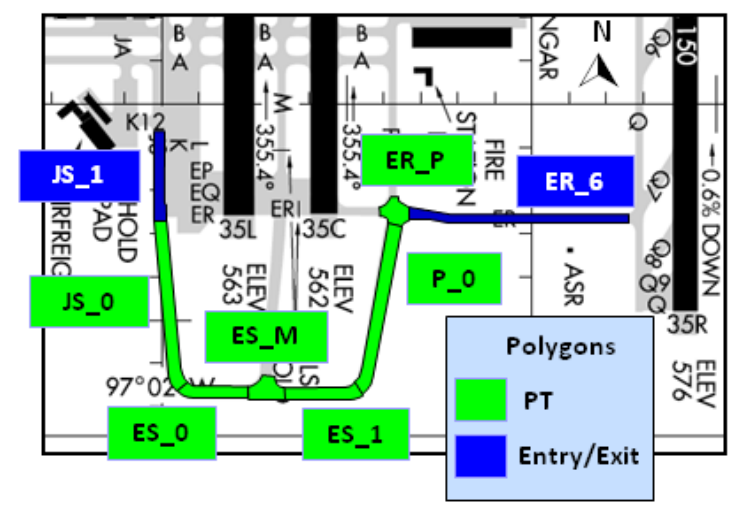

a) Polygons used when taxiing via PT

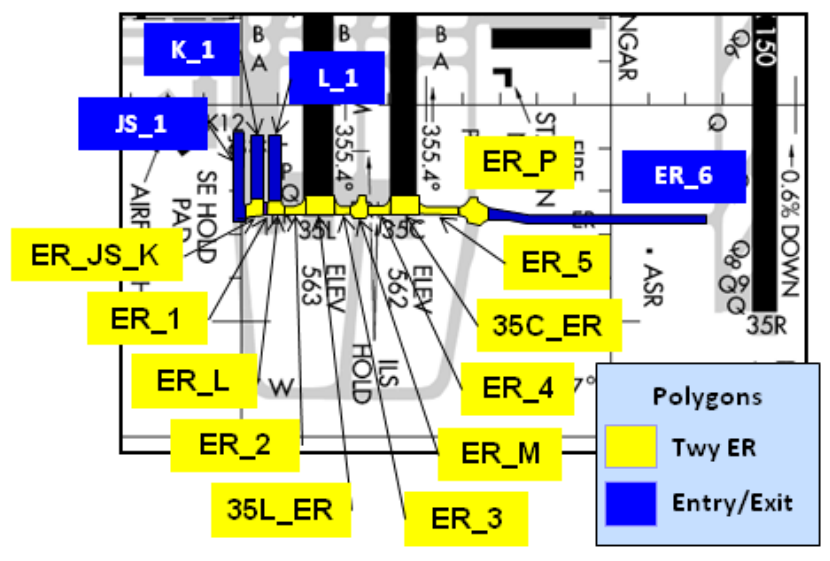

b) Polygons used when crossing $17 C \& 17 R$ via Twy ER

Figure 6. SODAA polygons for perimeter taxiway usage and local taxi time analysis.

\section{Local Taxi Time Analysis}

The local taxi time analysis seeks to quantify the difference in time required to taxi via the perimeter taxiway versus the time required to travel the much shorter distance via taxiway ER while crossing runways $17 \mathrm{C}$ and $17 \mathrm{R}$. In simple terms, this method involves establishing gates or triggers to record entry/exit times as a flight travels via one taxiway path or the other.

SODAA includes a "geospatial query" function which enables a researcher to run entry/exit queries on an arbitrary, user-defined polygon. This function is very useful and would seem to be ideal for establishing the entry/exit trigger points; however these queries can be slow for large data sets since tracks for every flight must be retrieved from the database and compared against the geospatial region.

The alternative solution presented here takes advantage of the fact that SODAA automatically computes and stores a huge number of polygon entry/exit times during the initial data import process. SODAA analyzes each flight's track data and identifies entry/exit times for each polygon the flight transits.

Figure 6a shows the taxiway polygons defined in the airport adaptation that lie on the perimeter taxiway, as well as the polygons that lie just before and just after the polygons defining the local taxi space. For the perimeter taxiway times, the entry time into polygon ER_P (where an aircraft has to commit to either the perimeter taxiway or a different taxiway path) was subtracted from the entry time into polygon JS_1 (where an aircraft emerges from the west side of the perimeter taxiway).

Figure 6b shows the taxiway polygons that lie on taxiway ER as defined in the airport adaptation, as well as the polygons that lie just before and just after the polygons defining the local taxi space. For taxiway ER local times, the entry time into polygon ER_P (where an aircraft has to commit to the taxiway path that will be used) was subtracted from the entry time into polygon L_1, K_1, or JS_1 (where an aircraft turns onto one of the three possible northbound taxiways).

Using these pre-defined taxiway polygons makes this analysis very efficient; however, it will introduce a slight bias in the data. The PT and ER paths share a starting point (see polygon ER_P in Fig. 6), but they may have 
different "finish lines.” The PT path always terminates at polygon JS_1. The ER path may terminate at any of three polygons: L_1, K_1 or JS_1. This "finish line” discrepancy will slightly bias local taxi times in favor of the taxiway ER path.

\section{Global Taxi Time Analysis}

The movement area taxi time analysis was performed to determine how use of the perimeter taxiway affected overall taxi times. The Movement Area Taxi Time (MATT) derived variable in SODAA is defined as the difference between On Time and Spot Crossing Time. SODAA's position-derived On Time is an approximation of actual On Time based upon track data entering the runway polygon (i.e. threshold crossing time). Spots or Apron Entry/Exit Points (AEPs) are the demarcation between movement and non-movement areas. SODAA's Spot Crossing Time is the time at which a flight's track history crossed nearest to a spot. In other words, the MATT variable accounts for all of the time an aircraft spent in the movement area (threshold crossing to spot crossing), but it does not consider time spent in the ramp area.

This particular analysis looks at MATT values both globally and sorted by destination terminal, since some of the terminals are much farther from the perimeter taxiway. Unlike the local taxi times, MATT times were computed for all 17L arrival traffic regardless of taxiway used.

\section{Results}

This section presents results for the three categories of analysis: perimeter taxiway usage, local taxi time and global taxi time. Unless otherwise noted, results are from the first sixteen months of perimeter taxiway operations: 22 December 2008 through 30 April 2010.

\section{A. Perimeter Taxiway Usage}

The usage count analysis is a relatively straightforward tabulation of perimeter taxiway operations. SODAA was used to detect instances of perimeter taxiway usage and to identify the associated arrival runway. SODAA track plots were used to verify data accuracy and then the data were exported to a spreadsheet for cumulative tabulation over the course of the study period.

As noted in the background section, only two arrival runways (17C and 17L) have the potential to deliver aircraft to the perimeter taxiway. Daily perimeter taxiway usage counts for these two runways are plotted in Fig. 7 . Counts for runway 17L are plotted in blue. Runway 17C counts are also included on the plot in green; however, they are essentially invisible at this scale. During the sixteen-month study period 6,282 perimeter taxiway operations were observed. Runway 17L arrival traffic accounts for nearly 99\% of those operations.

The table in the upper right corner of Fig. 7 summarizes the top five days of perimeter taxiway usage during the study period. As can be seen on the chart these were also the only days where perimeter taxiway operations exceeded 250. The orange rectangle denotes a several month period during which the ASDE-X surveillance data exhibited frequent dropouts in the extreme southern portions of the perimeter taxiway. These data dropouts significantly impacted the taxi time

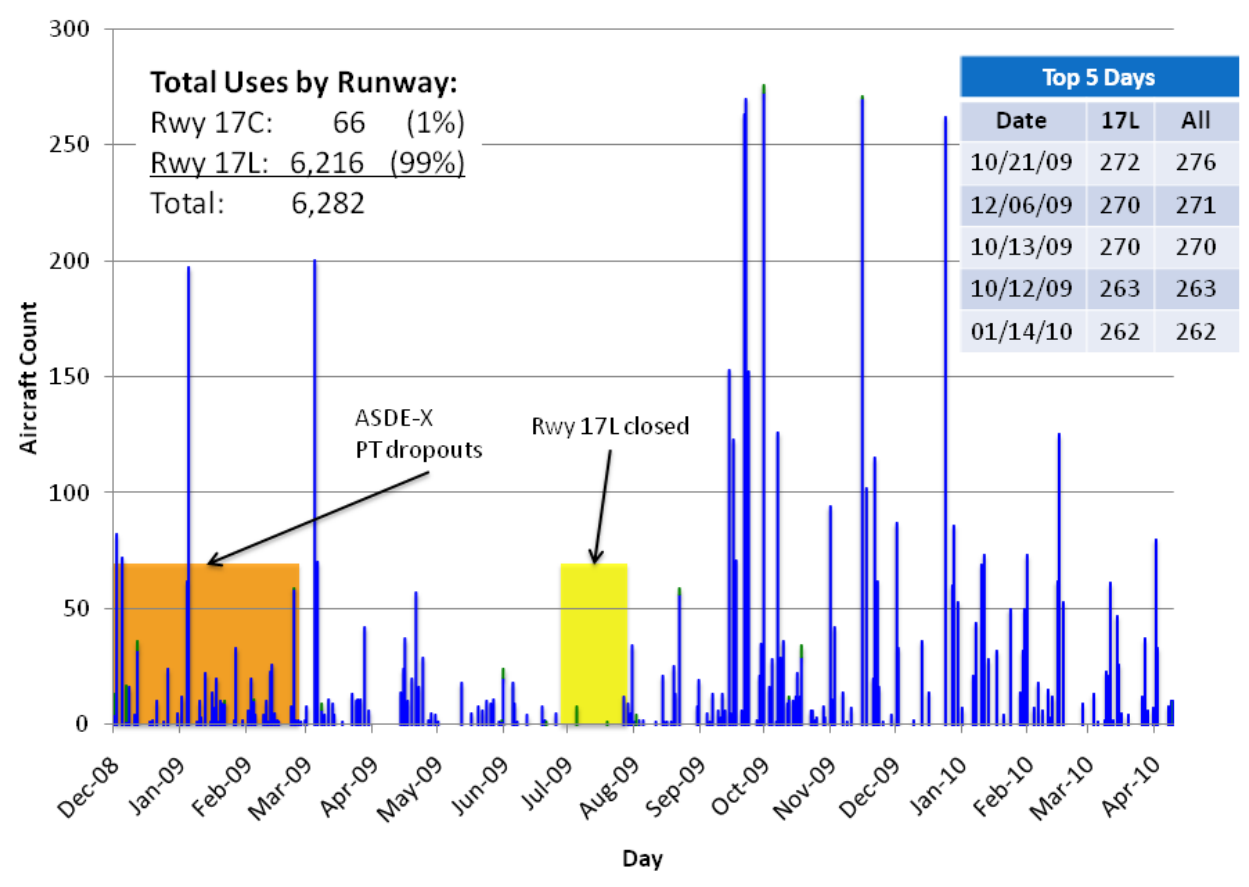

Figure 7. DFW perimeter taxiway usage: 22 Dec 2008 to 30 Apr 2010. 7

American Institute of Aeronautics and Astronautics 
computations presented later; however, usage counts were largely unaffected. The yellow rectangle denotes a onemonth period (18 July 2009 to 16 August 2009) when runway 17L was closed for asphalt resurfacing of the runway shoulders. This runway closure significantly impacted perimeter taxiway traffic counts during that time.

Since the overwhelming majority of perimeter taxiway operations are from runway $17 \mathrm{~L}$, it makes sense to consider perimeter taxiway usage in terms of runway 17L arrival traffic rather than overall DFW traffic counts. Table 1 presents monthly perimeter taxiway usage normalized by runway $17 \mathrm{~L}$ arrival traffic. To provide context the runway 17L arrivals are also compared to overall DFW arrivals and overall DFW arrivals for days when runway $17 \mathrm{~L}$ was used.

The data in Table 1 exhibit some interesting month-to-month variations. July and August 2009 show very low 17L utilization due to the aforementioned runway closure. October 2009 saw exceptionally high 17L and PT utilization. This is most likely due to an extended period of low-visibility conditions that motivated higher 17L utilization. For the overall sixteen-month study period, 6.4\% of DFW arrivals used runway 17L considering only those days when that runway was in use. Approximately 35\% of those runway 17L arrivals used the perimeter taxiway.

Table 1. DFW perimeter taxiway usage normalized by runway 17L arrival traffic: 22 Dec 2008 to 30 Apr 2010.

\begin{tabular}{|c|c|c|c|c|c|c|c|}
\hline \multirow[b]{2}{*}{ Year/Month } & \multirow[b]{2}{*}{$\begin{array}{c}\text { All } \\
\text { arrivals }\end{array}$} & \multicolumn{4}{|c|}{$17 \mathrm{~L}$ arrival traffic } & \multicolumn{2}{|c|}{$\begin{array}{c}\text { PT usage by } 17 L \text { arrival } \\
\text { traffic }\end{array}$} \\
\hline & & $\begin{array}{c}\text { Days } \\
17 \mathrm{~L} \\
\text { used }\end{array}$ & $\begin{array}{l}\text { All arrivals } \\
\text { on days } \\
17 \text { used }\end{array}$ & $\begin{array}{c}17 \mathrm{~L} \\
\text { arrivals }\end{array}$ & $\begin{array}{l}\% \text { of all } \\
\text { arrivals on } \\
\text { days } 17 \mathrm{~L} \\
\text { used }\end{array}$ & Uses & $\begin{array}{l}\% \text { of } 17 \mathrm{~L} \\
\text { arrivals }\end{array}$ \\
\hline 2008/12* & 5,157 & 7 & 3,429 & 406 & $11.8 \%$ & 175 & $43.1 \%$ \\
\hline 2009/01 & 26,221 & 21 & 17,953 & 1,255 & $7.0 \%$ & 361 & $28.8 \%$ \\
\hline $2009 / 02$ & 24,285 & 21 & 18,502 & 1,084 & $5.9 \%$ & 173 & $16.0 \%$ \\
\hline $2009 / 03$ & 25,981 & 24 & 20,749 & 1,417 & $6.8 \%$ & 433 & $30.6 \%$ \\
\hline $2009 / 04$ & 25,883 & 25 & 21,505 & 1,165 & $5.4 \%$ & 118 & $10.1 \%$ \\
\hline $2009 / 05$ & 22,101 & 22 & 16,762 & 1,117 & $6.7 \%$ & 219 & $19.6 \%$ \\
\hline $2009 / 06$ & 26,708 & 26 & 23,143 & 1,278 & $5.5 \%$ & 117 & $9.2 \%$ \\
\hline $2009 / 07 * *$ & 28,119 & 15 & 13,625 & 689 & $5.1 \%$ & 19 & $2.8 \%$ \\
\hline $2009 / 08 * *$ & 26,204 & 12 & 10,985 & 389 & $3.5 \%$ & 65 & $16.7 \%$ \\
\hline $2009 / 09$ & 26,343 & 18 & 15,537 & 603 & $3.9 \%$ & 171 & $28.4 \%$ \\
\hline $2009 / 10$ & 26,795 & 21 & 18,123 & 2,086 & $11.5 \%$ & 1,630 & $78.1 \%$ \\
\hline $2009 / 11$ & 23,739 & 22 & 15,605 & 1,015 & $6.5 \%$ & 295 & $29.1 \%$ \\
\hline $2009 / 12$ & 27,222 & 18 & 15,247 & 1,433 & $9.4 \%$ & 718 & $50.1 \%$ \\
\hline 2010/01 & 25,170 & 21 & 16,668 & 1,034 & $6.2 \%$ & 652 & $63.1 \%$ \\
\hline $2010 / 02$ & 23,496 & 14 & 11,979 & 823 & $6.9 \%$ & 387 & $47.0 \%$ \\
\hline $2010 / 03$ & 27,340 & 18 & 16,228 & 944 & $5.8 \%$ & 339 & $35.9 \%$ \\
\hline $2010 / 04$ & 25,117 & 23 & 19,600 & 847 & $4.3 \%$ & 344 & $40.6 \%$ \\
\hline Overall & 415,881 & 328 & 275,640 & 17,585 & $6.4 \%$ & 6,216 & $35.3 \%$ \\
\hline
\end{tabular}

8

American Institute of Aeronautics and Astronautics 


\section{B. Local Taxi Time Results}

The local taxi time analysis quantifies the difference in time required to taxi via the perimeter taxiway versus the time required to travel the much shorter distance via the nearest alternative. Taxiway ER is approximately 3,300 feet from the taxiway P intersection on the east to the taxiway JS intersection on the west (see ER_P and JS_1 polygons in Fig. 6a). The alternative path between these endpoints around the PT is approximately 7,800 feet. Thus, the PT path is approximately 4,500 feet longer than the path along taxiway ER that crosses the departure ends of runways 17C and 17R.

Unimpeded taxi times along these two paths are easily computed and clearly favor the ER path. Of course, the primary advantage of the perimeter taxiway is that it avoids all runway crossings. Taxiway ER traffic will very likely have to hold for runway 17C arrivals and for runway 17R departures. Those potential holds for runway crossings can result in significantly longer local taxi times for aircraft using taxiway ER.

As noted above, the ASDE-X surface surveillance system provided relatively poor coverage for the extremities of the perimeter taxiway during the first few months of perimeter taxiway operations. The data dropouts as aircraft transited the southern edge of the perimeter taxiway made it nearly impossible to compute accurate taxi times. The PT surveillance problems have been mostly resolved with a prototype ASDE-X software change on 15 March 2009 and introduction of the production ASDE-X system on 9 March 2010. Thus, taxi time analyses for the perimeter taxiway were performed from 15 March 2009 through the end of the study period - 30 April 2010.

Taxiway ER times were analyzed from 15 March 2009 to 30 Sep 2009 when the SODAA adaptation was changed. The SODAA change improved the taxiway polygon layout but prevented a direct comparison between polygon entry/exit times processed before and after the adaptation change. The ER sample size of 1961 flights for this period was deemed sufficiently large to forego reprocessing the data.

Table 2 summarizes the local taxi time results. As expected, the shortest local taxi time (less than one minute) is along taxiway ER. This path also has the longest local taxi time (more than 12 minutes). Average taxi times on ER are 45 seconds shorter than the perimeter taxiway path. Taxi times on the perimeter taxiway show significantly less variability with standard deviation values approximately half of those found for taxiway ER traffic.

Table 2. Comparison of local taxi times via taxiway ER to those via the perimeter taxiway.

\begin{tabular}{|c|c|c|c|}
\hline Category & Taxi via ER & Taxi via PT & $\begin{array}{c}\text { Difference } \\
\text { (PT-ER) }\end{array}$ \\
\hline Count & $1,961^{*}$ & $2,382 * *$ & - \\
\hline Max & $12: 10$ & $7: 52$ & $-4: 18$ \\
\hline Min & $0: 56$ & 1:59 & $1: 03$ \\
\hline Mean & $3: 17$ & 4:02 & $0: 45$ \\
\hline Median & 2:56 & $3: 57$ & 1:01 \\
\hline Std. Dev. & $1: 33$ & $0: 45$ & $-0: 48$ \\
\hline \multicolumn{4}{|c|}{ Counts for each exit polygon used (see Fig. 6) } \\
\hline JS_1 & $94(5 \%)$ & 2,382 & - \\
\hline K_1 & $1,461(75 \%)$ & - & - \\
\hline L_1 & $406(20 \%)$ & - & - \\
\hline
\end{tabular}

The bottom portion of Table 2 addresses the "finish line" discrepancy described in the methodology section. The table shows that only 5\% of taxiway ER traffic exited via the JS_1 polygon (see Fig. 6) used by PT traffic. Thus, 95\% of ER traffic benefitted from the shorter "finish lines" associated with polygons K_1 and L_1. This discrepancy biases the times for ER traffic.

The significance of this bias may be assessed with a simple distance/speed calculation. The three north-south taxiways (L, K and JS) are each about 270 feet apart. Taxiway ER traffic must make a 90 degree turn onto one of the north-south taxiways; therefore, it is reasonable to assume an average speed of 15 knots as aircraft traverse the western portion of ER. Thus, an aircraft exiting taxiway ER via polygon K_1 will have a transit time about 11 seconds shorter than the same aircraft exiting via polygon JS_1. One could account for this bias by increasing the average ER local taxi time from 3:17 to 3:28 for the 75\% of ER traffic that turns north on taxiway K. Similarly, ER transit times for traffic turning north on taxiway L will be biased by about 22 seconds. Stated another way, the taxiway ER average taxi time advantage of 45 seconds may be reduced to 34 seconds or 23 seconds for $95 \%$ of the traffic. 
Figure 8 presents the local taxi time results in graphical form. This histogram sorts the taxi time observations into 15-second bins. The 1,961 taxiway ER observations are shown in blue while the 2,382 PT observations are shown in green. This figure clearly shows the tighter distribution for PT taxi times when compared to taxiway ER times. This is visual confirmation of the results presented in Table 2 which shows a PT taxi time standard deviation that is approximately half that of the ER taxi time

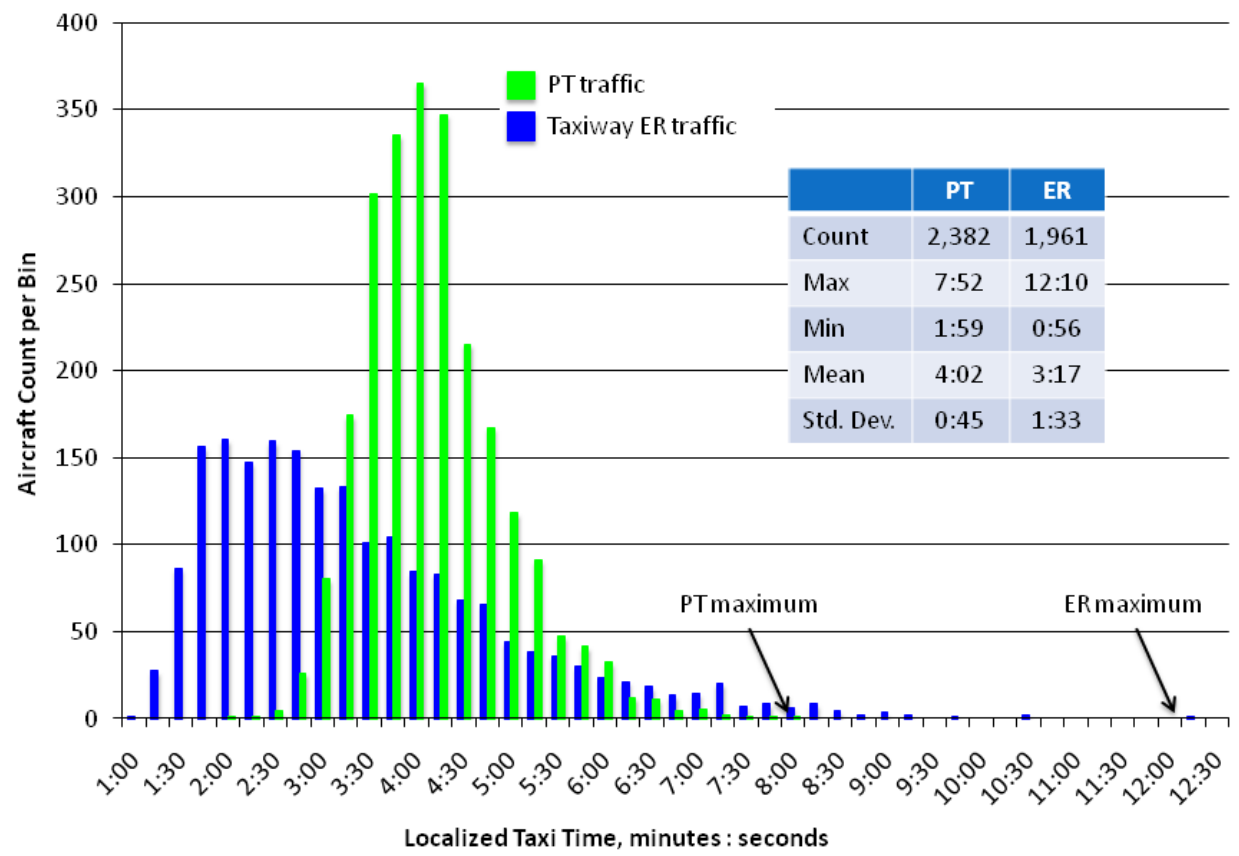
standard deviation.

Thus, using the perimeter taxiway decreases the variability of the local taxi times, potentially improving the consistency of overall taxi times. Also, the maximum local taxi time is effectively capped by using the perimeter taxiway. The predictable PT minimum taxi time provides a possible source of guidance for use of the perimeter taxiway. When local taxi times via taxiway ER rise above the PT minimum taxi time (about 2 minutes) controllers may be advised to route $17 \mathrm{~L}$ arrivals via the perimeter taxiway.

The cumulative distribution graph shown in Fig. 9 provides another view of these data. For each taxiway, the results are graphed as a percentage of the whole. The green curve shows data for the perimeter taxiway; the blue curve shows data for taxiway ER. This graph shows that $50 \%$ of ER traffic completes the local taxi segment in about 3 minutes while it takes about 4 minutes for the same percentage of PT traffic to complete that segment.

The cross-over point occurs near 4 minutes, 45 seconds, at which time $85 \%$ of all aircraft have completed the

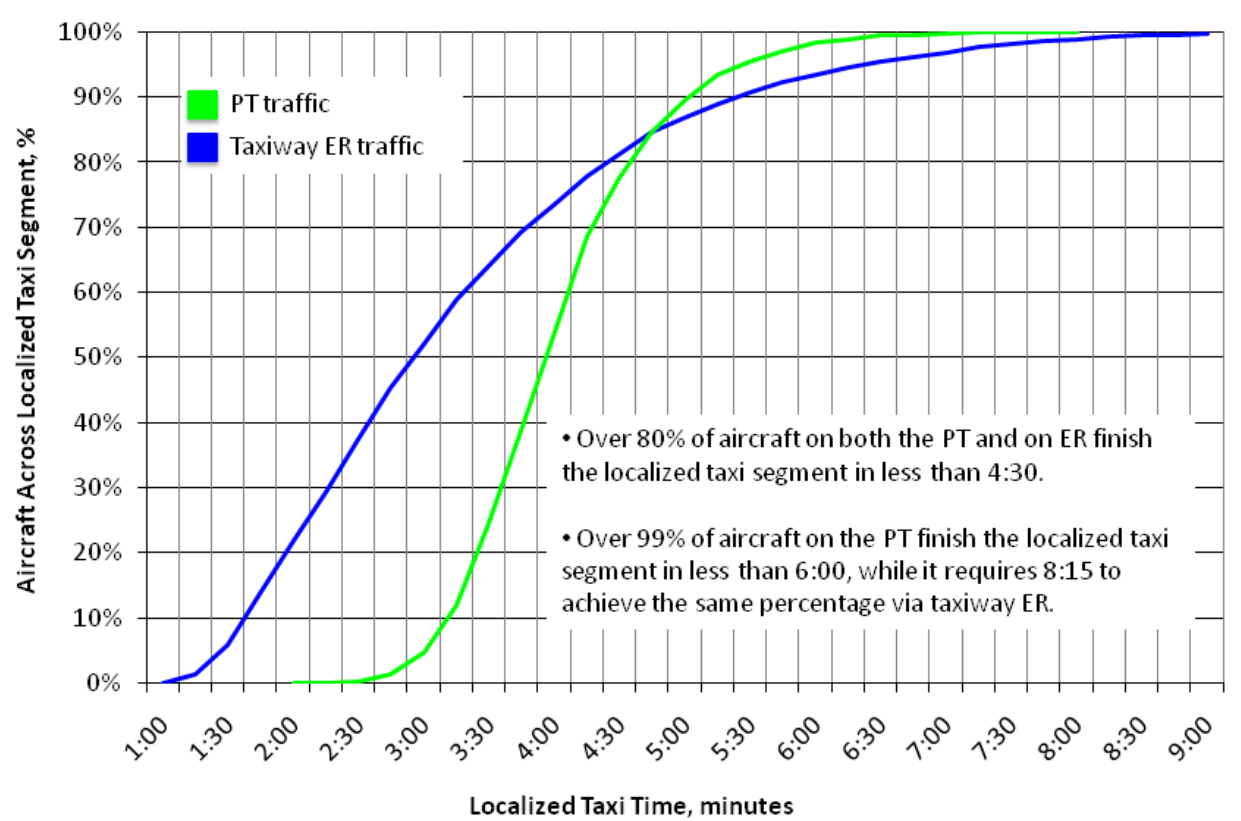
local taxi segment, whether they taxied via the perimeter taxiway or taxiway ER.

Over $99 \%$ of the aircraft taxiing on the PT complete that segment in less than 6 minutes, while it takes more than 8 minutes, to achieve the same percentage when taxiing via taxiway ER.

Figure 9. Local taxi time cumulative distribution.

American Institute of Aeronautics and Astronautics 


\section{Global Taxi Time Results}

The local taxi time results presented in the previous section provide a useful comparison between observed transit times on the perimeter taxiway and those on the closest alternative route (taxiway ER). One can argue, however, that the most important consideration is global taxi time (i.e. runway ON time to gate IN time) since this is more directly related to air carrier on-time performance and operating cost measures. Ramp area operations introduce a high degree of variability and uncertainty in the overall taxi time. Consequently, this analysis considers only taxi time in the movement area (i.e. runway ON time to spot crossing time) so as to maintain focus on any overall taxi time impacts due to perimeter taxiway usage.

As described in the methodology section, this analysis utilized SODAA's standard movement area taxi time (MATT) parameter which is a derived data element computed for all flights processed by SODAA. This MATT analysis focuses exclusively on runway 17L arrivals, since they account for $99 \%$ of perimeter taxiway operations. MATT data for 17L arrivals were examined for the period from 15 March 2009 to 30 April 2010.

Table 3 summarizes the MATT results. The upper portion of the table presents results for all taxiways other than the PT while the lower portion presents statistics for the PT. Taxi path distances from runway 17L vary widely depending on the flight's destination terminal. Consequently, Table 3 statistics are presented by terminal as well as for the overall set. See Figs. 1 and 5 for DFW terminal/ramp area locations.

Table 3. Movement area taxi time (MATT) values for 17L arrival traffic: 15 Mar 2009 to 30 Apr 2010

\begin{tabular}{|c|c|c|c|c|c|c|}
\hline & \multicolumn{3}{|c|}{ East ramp areas } & \multicolumn{2}{c|}{ West ramp areas } & \\
\hline & A & C & E & B & D & overall \\
\hline All taxiways other then perimeter taxiway (non-PT) \\
\hline Count & 1,583 & 1,937 & 702 & 1,690 & 806 & 6,718 \\
\hline Max & $38: 16$ & $42: 14$ & $17: 40$ & $26: 59$ & $40: 26$ & $42: 14$ \\
\hline Min & $6: 12$ & $5: 39$ & $4: 32$ & $5: 26$ & $7: 16$ & $4: 32$ \\
\hline Mean & $11: 31$ & $10: 34$ & $8: 31$ & $11: 19$ & $13: 48$ & $11: 09$ \\
\hline Median & $11: 05$ & $10: 05$ & $8: 09$ & $11: 09$ & $13: 09$ & $10: 46$ \\
\hline Std. Dev. & $2: 44$ & $3: 00$ & $1: 56$ & $2: 16$ & $3: 29$ & $3: 02$ \\
\hline Perimeter taxiway (PT) & \multicolumn{5}{|l|}{} \\
\hline Count & 770 & 874 & 274 & 139 & 315 & 2,372 \\
\hline Max & $42: 51$ & $63: 03$ & $14: 22$ & $45: 13$ & $53: 53$ & $63: 03$ \\
\hline Min & $7: 47$ & $7: 05$ & $6: 12$ & $9: 17$ & $9: 30$ & $6: 12$ \\
\hline Mean & $13: 00$ & $11: 43$ & $9: 17$ & $13: 15$ & $14: 45$ & $12: 21$ \\
\hline Median & $12: 34$ & $11: 10$ & $9: 12$ & $12: 57$ & $13: 57$ & $11: 57$ \\
\hline Std. Dev. & $2: 38$ & $3: 22$ & $1: 24$ & $3: 17$ & $4: 35$ & $3: 30$ \\
\hline
\end{tabular}

As shown in the table, the global taxi time study examined about 9,000 flights (6,718 non-PT and 2,372 PT) over a little more than 13 months. Table 1 indicates that there were about 14,000 runway 17L arrivals during this period. MATT values could not be computed for about $35 \%$ of runway $17 \mathrm{~L}$ arrivals due to incomplete ASDE-X track data or otherwise invalid spot-crossing times. However, the sample sizes are sufficiently large to provide meaningful results.

The MATT statistics presented in Table 3 are for all valid 17L arrival traffic including obvious outliers. Examination of several outliers reveals that these flights were held at various locations in the movement area presumably due to ramp or gate congestion. These outliers primarily affect the maximum values, so these should be discounted when evaluating the MATT results.

The minimum values presented in Table 3 are, however, of interest. Due to the significant sample sizes that were examined, these minimum MATT values will approximate unimpeded taxi times from runway 17L to a given terminal via the shortest taxi path. It is interesting to note that minimum taxi times via the PT are less than 2 minutes longer than other taxi path options for all three east-side ramp areas. The difference in minimum MATT is larger (up to 3 minutes 13 seconds) for the two west-side ramp areas because non-PT taxi paths via the north bridge are significantly shorter than the PT taxi path. 
The overall average MATT shows a 72 second advantage for taxi paths other than the PT. It is interesting to note how the difference between PT and non-PT average values for the west-side ramp areas is much smaller than the difference between the minimum values. This indicates that surface traffic congestion reduces the shorter-distance advantage of the north-bridge taxi paths.

The MATT standard deviations are markedly different than those seen in the local taxi time analysis. PT standard deviation was half that of taxiway ER for the local analysis. For the MATT analysis the PT and non-PT standard deviations are nearly the same (PT standard deviation is about $15 \%$ greater). Upon reflection, this is not surprising as the many variables encountered during the global taxi operation seem likely to overwhelm any local reductions in variability provided by the PT taxi segment.

MATT statistics for the Terminal E ramp area deserve special mention. This terminal's proximity to the PT (see Figs. 1 and 5) make the PT seem an obvious choice for 17L arrivals destined for Terminal E. The results in Table 3 show that the average MATT is only 46 seconds longer for PT traffic than for non-PT traffic. Also, this is the only ramp area for which the PT path standard deviation is smaller than that for non-PT paths. The fact that these globallevel results for the Terminal E ramp area (the ramp area nearest the PT) closely parallel the local-level results presented in the previous section suggests that the increased variability (i.e. wider distribution) of PT MATT values relative to PT local times is due to factors elsewhere in the movement area and not to the PT itself.

Figure 10 presents the MATT results in graphical form. This histogram sorts the overall MATT observations into 30-second bins. The 6,718 non-PT observations are shown in blue while the 2,372 PT observations are shown in green. As noted in the figure, this histogram has been truncated at 30 minutes removing the outlier observations described above.

This histogram provides visual confirmation of the MATT results presented in Table 3. One can see that the PT and non-PT graphs have very similar distributions. The peak (i.e. approximate mean) of the PT histogram is shifted a little more than one minute to the right of the non-PT histogram peak.

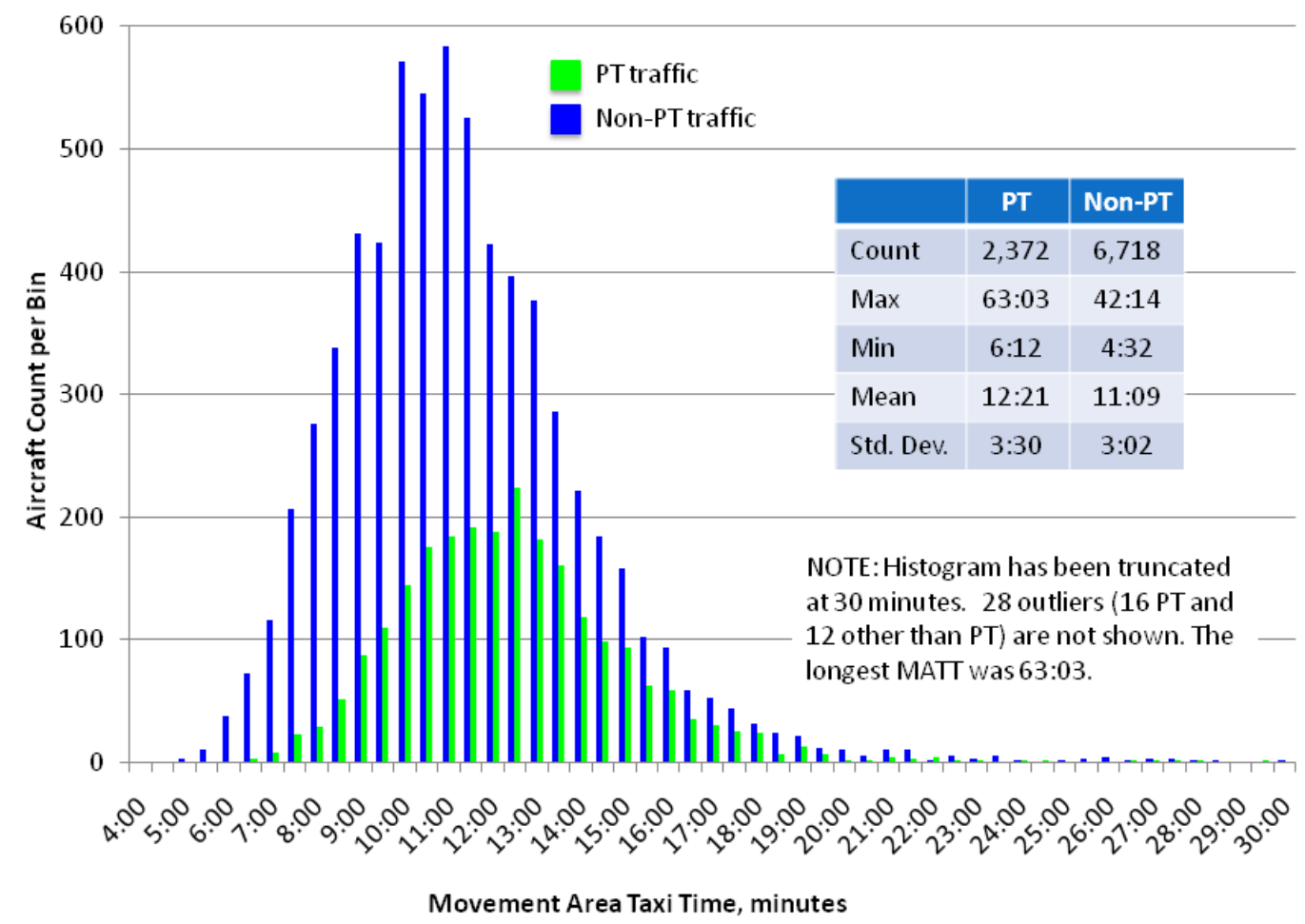

Figure 10. Movement Area Taxi Time (MATT) histogram: 30 second bins. 


\section{Assessing the Impact of Runway Crossing Clearance Policy Change}

In June 2010, the FAA issued a notice ${ }^{12}$ changing the agency's policy regarding runway crossing clearances. This policy change primarily impacts airports with 1,000 feet or more between runway centerlines where multiple runway crossing clearances are no longer allowed. Under the new policy, an air traffic controller is only allowed to issue a clearance for a single runway crossing at a time. The controller must observe the aircraft cross the first runway prior to issuing a clearance to cross the second runway

At DFW, runways 17R and 17C are separated by 1,200 feet. All 17L arrival traffic must cross these runways (subject to the new runway crossing clearance policy) or use the perimeter taxiway. Considering this new policy in light of the results presented above, one would expect: (1) a measurable increase in the local taxi time values for all 17L arrivals using the taxiway ER path, (2) a measurable increase in global taxi times for all 17L arrivals using nonPT paths, and (3) a likely increase in PT utilization by 17L arrival traffic.

The new policy went into effect on 30 June 2010. PT usage has been analyzed for the month of July 2010 yielding some interesting results. July saw a total of 2,235 PT operations. 121 of these were runway 17C arrivals while 2,152 were runway $17 \mathrm{~L}$ arrivals. There were 3,254 runway $17 \mathrm{~L}$ arrivals during the month of July.

Comparing these values to the results in Table 1 we find that perimeter taxiway usage for July is about three times that of all previous months with the exception of October 2009. During July, approximately $66 \%$ of runway 17L arrivals used the PT. This is nearly double the $35 \%$ usage rate observed during the study period and supports the hypothesis that the new policy will motivate higher PT utilization for $17 \mathrm{~L}$ arrival traffic.

It is interesting to note that runway 17C perimeter taxiway usage for July is higher than normal. During the sixteen-month study period runway 17C arrivals accounted for about $1 \%$ of PT operations. During July that value rose to $5 \%$. However, this increased utilization is largely attributable to two anomalous days (July $2^{\text {nd }}$ and July $9^{\text {th }}$ ) where 17C usage of the perimeter taxiway significantly exceeded 17L usage.

This quick-and-dirty analysis of July 2010 PT operations must be accompanied by a caveat. DFW's runway 18R/36L (a primary west-side arrival runway) was closed for a fifty-day pavement rehabilitation project beginning on 9 July 2010. During this closure, arrivals that would normally use runway 18R were redirected to the other three south-flow arrival runways: 13R, 17C and 17L. Thus, the runway 18R closure artificially inflated runway 17L arrival counts for two-thirds of July. This can be seen by comparing the 3,254 runway 17L arrivals for July 2010 to the values in Table 1 which show a monthly average of about 1,070 for 17L arrivals.

\section{Conclusion}

Sixteen months of DFW perimeter taxiway operations have been analyzed. ASDE-X surface surveillance data in combination with other data sources and a sophisticated analysis tool have enabled precise counts of perimeter taxiway usage and assessments of real-world taxi time impacts on both the local and global levels.

The results of this study can be summarized by several key observations. The PT is used almost exclusively by runway $17 \mathrm{~L}$ arrival traffic. Approximately $35 \%$ of runway $17 \mathrm{~L}$ arrivals use the perimeter taxiway. At the local level, taxi times around the PT average 45 seconds longer than times via the ER path crossing runways 17C and 17R. These PT times are, however, less variable than times via the ER path. At the global level, taxi times for aircraft using the PT average 72 seconds longer than those for aircraft using other taxi paths. Variability is about the same regardless of path. The data suggest that other movement area traffic factors overwhelm the PT variability advantage observed at the local level.

One objective of this study was to help refine guidelines for perimeter taxiway operations. The guidelines presented here are based solely on observed usage patterns and taxi time measurements and do not consider other factors (e.g. runway crossing or controller workload reductions). The local taxi time analysis suggests that ER taxi path transit times may be used as a trigger for PT usage. When the ER path taxi times rise above the PT path minimum time (about 2 minutes) then traffic should be routed via the PT. The global-level analysis suggests that the PT is a good option for all 17L arrivals destined to Terminal E due to the small (46 seconds) average taxi time penalty and less variable movement area taxi times.

The observations from this study are generally consistent with projections from fast-time and real-time simulation experiments which showed modest increases for inbound taxi times for most aircraft using the PT. However, comparison to previous simulation results is problematic due to significantly different operational scenarios and traffic levels. The most interesting comparisons to make would be those related to airport throughput (i.e. perimeter taxiway impact on arrival/departure rates); however, present perimeter taxiway usage represents too small a fraction of the overall operation (approximately 2\% of all DFW arrivals use the perimeter taxiway) to produce a measurable effect. 
Early indications are that the recent FAA policy change regarding multiple runway crossing clearances will have a significant impact on DFW perimeter taxiway usage. Assessing the impact of this policy change will be an interesting topic for future work. Future work should also consider the impact of starts and stops during taxi operations from both economic (i.e. fuel burn, brake wear, etc.) and environmental (i.e. noise and emissions) perspectives. Large scale start/stop analyses will depend on enhancements to analysis tool filtering and dwell detection capabilities.

\section{References}

${ }^{1}$ Chandler, J., “The Perimeter Push,” Air Transport World, Vol. 6, No. 9, Sep. 2009, p. 69.

${ }^{2}$ Krakowski, H. (COO FAA Air Traffic Organization), "On the Outlook for Summer Air Travel: Addressing Congestion and Delay testimony before the Senate Committee on Commerce, Science and Transportation, Subcommittee on Aviation Operations, Safety, and Security,” 15 July 2008, URL: http://testimony.ost.dot.gov/test/pasttest/08test/krakowski3.htm [cited 18 August 2010].

${ }^{3}$ IFALPA, “New 'end-around' taxi procedure at Atlanta Hartsfield (KATL),” IFALPA Safety Bulletin, 10SAB10, 23 November 2009.

${ }^{4}$ DFW International Airport board, “Airport Development Plan,” 1997.

${ }^{5}$ FAA, "Airport Obstructions Standards Committee (AOSC) Decision Document \#03 Atlanta Runway 8R/26L End-Around Taxiway,” 12 July 2004.

${ }^{6}$ FAA, “Airport Obstructions Standards Committee (AOSC) Decision Document \#06 Dallas/Fort Worth (DFW) End-Around Taxiway System,” 8 June 2005.

${ }^{7}$ FAA, “Airport Obstructions Standards Committee (AOSC) Decision Document \#07 National Departure Case Standard for End-Around Taxiways,” 21 September 2006.

${ }^{8}$ Buondonno, K., and Price, K. "Dallas/Fort Worth International Airport Perimeter Taxiway Demonstration,” DOT/FAA Technical Note, DOT/FAA/CT-TN03/19, July 2003.

${ }^{9}$ Satyamurti, S., "Runway Incursion Mitigation, Capacity Enhancement, And Safety Improvements With Perimeter Taxiway Operations at Dallas Fort Worth International Airport,” Ph.D. Dissertation, University of Texas at Arlington, Arlington, TX, 2007.

${ }^{10}$ Brinton, C., Lindsey, J., and Graham, M., “The Surface Operations Data Analysis and Adaptation (SODAA) Tool: Innovations and Applications,” 29th Digital Avionics Systems Conference, Salt Lake City, Utah, October, 2010 (to be published).

${ }^{11}$ SODAA, Surface Operations Data Analysis and Adaptation tool, Software Package, Ver. 2.4.0, Mosaic ATM, Leesburg, VA, 2009.

${ }^{12}$ FAA, “Air Traffic Organization Policy Notice: Taxi and Ground Movement Operations,” DOT/FAA/ N JO 7110.532, 30 June 2010. 